\title{
Desastre Ambiental do Exxon Valdez: temática de planejamento didático no ensino de Biologia
}

\section{Exxon Valdez Environmental Disaster: didactic planning theme in Biology teaching}

\author{
Letiane Lopes da Cruz (letianedacruz@gmail.com) \\ Universidade Federal da Fronteira Sul - UFFS \\ Bolsista PIBID/CAPES
}

\begin{abstract}
Resumo: O relato descreve a construção, desenvolvimento e aplicação de uma aula realizada com uma turma de $2^{\circ}$ ano do Ensino Médio noturno de uma escola pública Estadual do município de Cerro Largo/RS, a atividade constituiu a elaboração de um plano de aula sobre o derrame de petróleo do navio Exxon Valdez, desenvolvido através do Projeto Interdisciplinar, sendo proposto pela disciplina de Prática de Ensino em Ciências e Biologia III -Metodologia e Didática no Ensino de Ciências e Biologia, a disciplina tem como finalidade integrar os alunos em formação inicial à realidade da sala de aula, buscando associar a teoria e prática.
\end{abstract}

Palavras-chave: Práticas de Ensino; Plano de Aula; Formação Inicial

Abstract: The report describes the construction, development and application of a class held with a 2 nd year high school class at a state public school in the municipality of Cerro Largo / RS, the activity was the elaboration of a lesson plan about the spill of Exxon Valdez, developed through the Interdisciplinary Project, being proposed by the discipline of Teaching Practice in Science and Biology III - Methodology and Didactics in Science and Biology Teaching, the purpose of this course is to integrate students in initial formation with the reality of classroom, seeking to associate theory and practice.

Keywords: Teaching Practices; Class plan; Initial formation.

\section{INTRODUÇÃO}




\section{Vol. 2, n. 3 - Edição Especial: Ciclos Formativos em Ensino de Ciências.}

O presente relato contempla a construção, desenvolvimento de um plano de aula e consecutivamente a aplicação deste, tendo como temática o derrame de Petróleo do Navio Exxon Valdez, realizado através do Componente Curricular de Prática de Ensino em Ciências e Biologia III - Metodologia e Didática no Ensino de Ciências e Biologia, a atividade foi realizada por acadêmicos da terceira fase do curso de Ciências Biológicas, e desenvolvido em uma turma de $2^{\circ}$ ano do Ensino Médio de Escola Estadual do Município de Cerro Largo/RS. A elaboração do plano contempla 4h/ aula, sendo que apenas $2 \mathrm{~h}$ /aulas foram efetivadas, por consequência do pouco tempo disposto para as atividades.

A Prática de Ensino em Ciências e Biologia III, assim como as outras práticas presentes no curso Ciências Biológicas, realizam o Projeto Interdisciplinar, o qual integra todos os componentes curriculares do semestre, buscando uma interligação entre estes, favorecendo para o processo de ensino-aprendizagem dos discentes. Este projeto refere-se a realização de um plano de aula sobre um desastre ambiental sobre o derrame de petróleo do navio Exxon Valdez, sendo abordado aspectos históricos, ecológicos, e ambientais, que esta grande tragédia causou aos seres vivos presentes naquele local.

Após concluído o plano de aula, realizamos 2h/aulas deste, no qual desfrutamos da oportunidade de realizar aquela associação discutida por muitos autores e professores, entre teoria-prática, buscar desenvolver os conhecimentos teóricos construídos na Universidade, e pôr em prática na escola, trabalhando no sentido da diversificação, inovação, também uma reflexão crítica sobre essa ação.

Assim como afirma Nóvoa (1992, p. 17) “A formação não se faz antes da mudança, faz-se durante, produz-se nesse esforço de inovação e de procura dos melhores percursos para a transformação da escola", é através dessa abordagem que as práticas de ensino se direcionam para a formação de professores. Esse autor também aborda menciona como são importantes as práticas em grupo, gerando uma "autonomia profissional, e consolidação da profissão na produção de saberes e valores", enquanto uma prática realizada individualmente propicia o isolamento, e a imagens de professores como meros transmissores de saberes.

\section{DESCRIÇÃO DAS ATIVIDADES}

A elaboração do plano de aula se realizou em grupo, através de um sorteio, obtivemos a temática a ser trabalhada referente a um desastre ambiental de um navio 


\section{Vol. 2, n. 3 - Edição Especial: Ciclos Formativos em Ensino de Ciências.}

petroleiro, o caso de Exxon Valdez, após reflexões e discussões no grupos, chegamos em um consenso na elaboração de um bloco de 4h/aulas, onde foram planejadas diferentes metodologias de ensino, tais como aulas expositivas e dialogadas, cartazes, esquemas e mapas conceituais, para assim conseguirmos discutir com os alunos de forma clara e precisa cada assunto abordado.

Após nosso plano de aula finalizado, fomos em busca de uma escola para ministrar nossas aulas, como se tornaria mais fácil, procuramos uma na cidade de Cerro Largo/RS, onde todos os integrantes do grupo poderiam estar presentes para a aplicação.

Sendo assim obtivemos uma turma de $2^{\circ}$ ano do Ensino Médio, após discussões, decidimos às $2 \mathrm{~h} /$ aulas que seriam aplicadas, por se tratar de conteúdos menos complexos, abordamos então na 1h/aula, de forma expositiva e dialogada, com a temática "o que seria um desastre ambiental? E como ocorreu esse desastre do Exxon Valdez.", elencando conteúdos sobre ecologia, níveis tróficos, cadeia alimentar, e um relato de como ficou o meio ambiente após o derrame de petróleo, os danos causados na flora e fauna local, após as discussões, um vídeo para finalizar as ideias sobre esse desastre.

$\mathrm{Na}$ segunda aula aplicada, no mesmo dia, último período de forma dialoga e expositiva, retomamos a discussão sobre o desastre Exxon Valdez, dando ênfase aos seres marinhos afetados no lugar que ocorreu o desastre, abordando parte da zoologia, destacando as principais classes do Filo Arthropoda, os principais representantes daquela região, também sendo discutida o efeito na economia daquele lugar, outro ponto afetado.

\section{DISCUSSÃO DO RELATO}

A partir de nossa primeira aula elaborada, mesmo sendo de forma simples, podemos perceber quanto os alunos obtiveram entendimento do assunto abordado, em um primeiro momento, todos pareciam impressionados com novas pessoas conduzindo às aulas, porém na $2^{\mathrm{a}} \mathrm{h} /$ aula, após o intervalo, a interação com os educandos, teve uma grande relevância, se envolveram no assunto abordado, fazendo perguntas em momentos de dúvidas, relacionando estas com situações presenciadas por eles em seu dia a dia. Formando assim um diálogo junto com os professores em formação, como Alro e Skovsmose(2006, p.69) trazem que "o ato de comunicação entre professores e alunos, podem favorecer a aprendizagem de maneira peculiar", então nesse processo coletivo de aprendizagem professor e aluno entram em sintonia, o professor para 


\section{Vol. 2, n. 3 - Edição Especial: Ciclos Formativos em Ensino de Ciências.}

compreender as ideias de seus alunos deve saber ouvir, e orientá-los no processo de aprendizagem, estabelecendo assim um contato entre os dois.

Antunes (2002) destaca a importância do diálogo para uma aprendizagem significativa, pois é por meio dele que é capaz de buscar saberes iniciais dos discentes, e a partir destes, construir o conhecimento. Diálogo também permite a troca de experiências, que torna as aulas mais interessantes e produtivas aos alunos.

Como método avaliativo formativo, este foi relacionado com a participação e interesse dos estudantes no decorrer da atividade, já que não conseguimos realizar as questões para discussão, por insuficiência do tempo,

\section{CONCLUSÃO}

A prática de ensino na formação de professores possui uma grande significância, por meio dela podemos refletir sobre nossa formação, é um espaço de aprendizagens e da construção da identidade profissional dos professores em formação, nos aproximam diretamente de nossa futura área de trabalho, formando uma inter-relação entre duas instituições de ensino, Escola e Universidade, cada um trazendo valores, objetivos, e relações diferentes, com apenas um único propósito, a formação de professores, através dessas relações tiramos lições necessárias para nossa formação (LIMA, 2008).

Diante de um conjunto de leituras, reflexões, conhecimentos e práticas durante a formação acadêmica, entre o escrito e o vivido, tem papel fundamental no processo de construção da identidade docente, pois essa identidade só é construída diante o confronto entre teoria e prática, um espaço de mediação reflexiva entre a universidade, escola e sociedade (PIMENTA; ANASTASIOU, 2002).

Com essa atividade percebemos o quanto o planejamento e a inserção em uma escola desde o início de nossa graduação é importante para a nossa formação acadêmica, como futuros professores de Ciências/ Biologia, associando a teoria com a prática.

\section{REFERÊNCIAS}

ALRO, H.; SKOVSMOSE, O. Diálogo e aprendizagem em Educação Matemática. Belo Horizonte: Autêntica, 2006. 
Revista Insignare Scientia

Vol. 2, n. 3 - Edição Especial: Ciclos Formativos em Ensino de Ciências.

ANTUNES, Celso. Professor bonzinho=aluno difícil: a questão da indisciplina em sala de aula. Petrópolis, RJ: Vozes, 2002.

LIMA, M.S.L.Reflexões sobre o Estágio/ Prática De Ensino na Formação de Professores. Rev. Diálogo Educ., Curitiba, v. 8, n. 23, p. 195-205, jan./abr. 2008

Disponível em: 〈https://periodicos.pucpr.br/index.php/dialogoeducacional/article/view/4015/3931 > Acesso em: Dez.2018.

NÓVOA, António. Os professores e a sua formação. Lisboa: Dom Quixote, 1992. ISBN 972-20-1008-5. pp. 13-33 . Disponível em: < http://repositorio.ul.pt/bitstream/10451/4758/1/FPPD_A_Novoa.pdf > Acesso em: Dez.2018.

PIMENTA, Selma Garrido; ANASTASIOU, Léa das Graças Camargo. Docência no ensino superior. São Paulo: Cortez, 2002. 